\title{
Air Exchange in urban canyons with variable building width: a numerical LES approach.
}

\section{Michela Garau*, Maria Grazia Badas, Simone Ferrari, Alessandro Seoni and Giorgio Querzoli}

DICAAR - Dipartimento di Ingegneria Civile, Ambientale e Architettura, Università degli Studi di Cagliari, via Marengo 2, 09123 Cagliari, Italy

Email: mi.garau@unica.it

Email:mgbadas@unica.it

Email: ferraris@unica.it

Email: aseoni@unica.it

Email: querzoli@unica.it

*Corresponding author

\begin{abstract}
The aim of this work is to gain further insight into the role played by the building aspect ratio $\left(\mathrm{AR}_{\mathrm{B}}\right.$, i.e. the ratio of the building width, $\mathrm{W}_{\mathrm{B}}$, to the building height, $\mathrm{H}$ ) and its influence on street canyon flow. We carried out a series of Large Eddy Simulations with arrays of obstacles with different widths, ranging from 0.5 to 2.0 , and two canyon aspect ratios $\left(\mathrm{AR}_{\mathrm{C}}\right.$, i.e. the ratio of the canyon width, $\mathrm{W}$, to $\mathrm{H}) \mathrm{AR}_{\mathrm{C}}=0.5$ and $\mathrm{AR}_{\mathrm{C}}=1.0$. Experimental data was obtained in a water channel for the corresponding configuration and used to validate numerical simulations. Results were found strongly dependent on the building aspect ratios, with two distinct behaviors identified with respect to the canyon aspect ratio. The residence time decreases with decreasing $\mathrm{AR}_{\mathrm{B}}$, irrespective of the canyon aspect ratio, suggesting that $A R_{B}$ and $A_{C}$ can be optimized to guarantee an optimal street canyon ventilation in urban planning.
\end{abstract}

Keywords: Urban Street Canyon, Large Eddy Simulation, Flow Exchange Rate, Building Aspect Ratio.

Reference to this paper should be made as follows: Garau. M., Badas, M.G., Ferrari, S., Seoni A. and Querzoli, G. (2019) 'Air Exchange in urban canyons with variable building width: a numerical LES approach', Int. J. Environment and Pollution, Vol. xx, xxxxxxxxx,

\section{Biographical notes:}

Michela Garau is a PhD student in Civil Engineering and Architecture. Her main research interests include boundary layer meteorology, numerical modelling of urban canopies and dispersion models. 
Author

Maria Grazia Badas has been an Aggregate Professor in Hydraulics II at the University of Cagliari (Italy), since 2006. She received her PhD in Territorial Engineering from the University of Cagliari in 2005. Her research topics include turbulence and mixing in civil, environmental and biological flows.

Simone Ferrari has been an Aggregate Professor in Fluid Mechanics at the University of Cagliari (Italy), since 2011. He received his PhD in Territorial Engineering from the University of Cagliari, in collaboration with the imperial College London (UK) in 2007. His research interests include turbulence and mixing in civil, environmental, industrial and biological flows.

Alessandro Seoni has been a Graduate Technician in Hydraulics and Hydraulic Structures and Infrastructures since 2007. He has been teaching assistant at the University of Cagliari in Hydrology and Hydraulic Structures since 2008, and in Hydraulics since 2013. He received his PhD in Territorial Engineering in 2014 from the University of Cagliari, Italy. His research interests include turbulence, hydrology and flow measurements.

Giorgio Querzoli has been a Full Professor in Fluid Mechanics at the University of Cagliari, Italy since 2006. He received his PhD in Environmental Monitoring at the University of Florence, Italy in 1996. He teaches 'Hydraulics' and 'Environmental Hydraulics'. His research topics are turbulence and dispersion in biologic and environmental flows, such as atmospheric boundary layer and ocean outfalls.

This paper is a revised and expanded version of a paper entitled The air quality in urban canyons with tight and wide buildings presented at the 18th International conference on Harmonisation within Atmospheric Dispersion Modelling for Regulatory Purposes. Bologna, Italy, October, October 9-12, 2017. The paper is submitted for a special issue with Silvana Di Sabatino and Silvia Trini Castelli as guest editors.

\section{Introduction}

The urban canopy is characterized by a wide range of elements (such as vegetation, traffic, buildings, balconies, etc.) and geometrical shapes interacting with the atmosphere. It is well known that the pollutant removal from a street canyon depends on the wind and on the air exchange mechanism between the street canyon and the overlying air (i.e. Soulhac et al., 2008; Salizzoni, 2006). As a consequence, its correct prediction plays a crucial role in planning of healthy urban areas. Several experimental and numerical studies dealt with urban flows over both simplified and complex building geometries, focusing on different spatial scales: street scale (of order $10-100 \mathrm{~m})$, neighbourhood scale $(100-1000 \mathrm{~m})$ or city scale $(1-20$ $\mathrm{Km})$. A recent work of Ricci et al. (2017) highlights the differences occurring in mean and turbulent flow, by means of urban area models with increasing levels of geometrical details. They pointed out how the significant deviations can be caused by geometrical simplifications, although underlining the huge computational power requested for 
numerical simulations with high level of detail. For this reason, when the accurate reproduction of geometric details is striking, RANS models are more widely employed, while LES is confined to single building configurations (see e.g. van Hooff and Blocken, 2010). In order to understand the influence due to shape variations and also to unveil the mechanism driving air ventilation and mixing process, the idealized and simplified geometries are preferred. These are the reasons why much attention was paid in literature to simple building configurations. For instance, Ferrari et al., (2016 and 2017) and Garau et al. (2017) made use of arrays of identical prismatic buildings and canyons, to study the influence of different roof shapes on turbulence and ventilation. Badas et al (2018-a) investigated the impact of rooftop stack position on the pollutant entrapment within 2D street canyon configurations in case of gabled buildings. Some authors considered isolated buildings immersed in a boundary layer in order to describe the main tridimensional flow structures, the pollutant dispersion and the influence of the body orientation with respect to the incoming flow (Castro and Robins, 1977; Martinuzzi and Tropea, 1993; Bernardino et al., 2017). Other studies (see e.g. Oke, 1988) focused on the flow regime changes occurring in idealized street canyons, depending on the canyon aspect ratio, $\mathrm{AR}_{\mathrm{C}}$ (which is defined as the ratio of street width to building height, $\left.A R_{C}=W / H\right)$ and the building length in the spanwise direction. Millward-Hopkins et al. (2011) summarized the overall effect of the area density and building height variability in an idealised city by using three-dimensional blocks. By employing cuboids with the $1 / \mathrm{H}$ ratio ranging from 0.3 to 3.0 and $\mathrm{W}_{\mathrm{B}} / \mathrm{H}$ from 0.5 to 5.0 , (where $\mathrm{H}, \mathrm{W}_{\mathrm{B}}$ and 1 are respectively, the building height, width and length in the spanwise direction), they described the individual building wakes, calculating the spanwise extent of sheltering $\left(\mathrm{L}_{\mathrm{W}}\right)$ and the rear reattachment length $\left(\mathrm{L}_{\mathrm{R}}\right)$. Moreover, they estimated the dependence of roughness length and the zero-plane displacement upon area density, via a quasi-empirical modelling approach. Zaki et al. (2011) performed windtunnel experiments on seven types of urban building arrays, varying the roughness packing densities. They found that the effects of the random distribution of the horizontal and vertical building dimensions on the aerodynamic parameters are mainly related to the vortex structures around the blocks, hence, concluding that the aspect ratio of the block is the appropriate index for their estimation. Regarding the building aspect ratio, $A R_{B}$ (i.e. the ratio of building streamwise width to height, $A R_{B}=W_{B} / H$ ), Hang and $\mathrm{Li}$ (2011) set up numerical simulations and wind tunnel experiments to evaluate the ventilation performance in the high-rise cities ( $\mathrm{H}$ ranging from $1.5 \mathrm{~W}_{\mathrm{B}}$ to $2.67 \mathrm{~W}_{\mathrm{B}}$ ). Similarly, Chan et al. (2003) carried out measurements on a three-dimensional arrangement of parallelepipedal buildings with different combinations of $\mathrm{AR}_{\mathrm{C}}$ (ranging from 0.5 to 3.0), 
$\mathrm{AR}_{\mathrm{B}}$ (ranging from 0.25 to 2.0 ) and varying the building length in the spanwise direction. However, while Hang and Li (2011) changed only the building height, Chan et al. (2003) varied also the building width.. Focusing on two-dimensional street canyons, most of the works reported in literature are aimed at evaluating the influence of the $\mathrm{AR}_{\mathrm{C}}$ on flow and pollutant dispersion. Brown et al., (2000) investigated mean and turbulent quantities for $\mathrm{AR}_{\mathrm{B}}=1.0$ and $\mathrm{AR}_{\mathrm{C}}=1.0$ by means of wind tunnel experiments. Neophytou et al., (2014), Di Bernardino et al., (2015a) reproduced the urban boundary-layer in a water channel with $\mathrm{AR}_{\mathrm{C}}$ ranging from 0.5 to 2.0. Other authors investigated the same configurations by means of numerical simulations (Chung and Liu, 2012; Wong and Liu, 2012). However, most of the works are focussed on $\mathrm{AR}_{\mathrm{C}}=1.0,2.0$, even if sometimes the range is extended down to 0.2 ( $\mathrm{Li}$ et al., 2008) with the aim to understand flow behaviour in cities where buildings are extremely tall, or up to 6.0 reproducing isolated buildings (see e.g. Garau et al., 2018). Even though two-dimensional street-canyons are widely studied, the effect of the building aspect ratio on street canyon flow and dispersion is still not clear. Actually, in case of real towns cities both and can be quite different from the typically analysed values (see Badas et al (2018-b) and reference therein).

In particular for narrowest street canyons, characterised by a poorer ventilation, every aspect should be considered to improve the air exchange. On this regard, the building to canyon width ratio may represent a simple but efficient parameter of influence. Therefore, we carried out a series of Large Eddy Simulations adopting different building and canyon aspect ratios in order to evaluate the impact of building width on the street-canyon flow. Arrays of two-dimensional buildings, immersed in a neutral boundary layer, were analysed in terms of velocity statistics and ventilation. The paper is organised as follows. Section 2 presents the numerical model, computational domain and numerical set-up. In section 3 , the validation of the model with literature data, other than the experimental and numerical results of the present simulations are

discussed. In section 4, conclusions are drawn, giving an overview of the limitations of the present work and forthcoming steps.

\section{Methods}

We focused on the flow in urban canyons formed by a virtually infinite array of buildings immersed in a neutrally-stratified boundary layer. Two canyon aspect ratios, $\mathrm{AR}_{\mathrm{C}}=0.5,1.0$ and four building aspect ratios, $\mathrm{AR}_{\mathrm{B}}=$ $0.5,1.0,1.5,2.0$ were considered, hence a total of 8 configurations were simulated. The wind direction was chosen orthogonal to the canyon axis in all the tests. A LES model was adopted to resolve the turbulent flow within 
and above the street canyons, which was validated with our water channel experimental data and other literature data in the cases of $\mathrm{AR}_{\mathrm{B}}=1.0$ and $\mathrm{AR}_{\mathrm{C}}=0.5,1.0$.

\subsection{Numerical Simulations}

We used of the open source library OpenFOAM 2.3.1, which solves the approximate form of the governing equations of the flow by means of the finite volume method (FVM). Following the classical LES scheme, the filtered governing equations are risolved using modelled sub-grid scale (SGS) motions for which we have employed the Smagorinsky model (Smagorinsky, 1963). Formally the LES decomposition into resolved and residual components is achieved by the convolution with a spatial filter function, which depends on the cut-off width $\Delta$. The resulting set of equations consists of the continuity equations and the filtered Navier Stokes equations:

$$
\begin{gathered}
\frac{\partial \bar{u}_{i}}{\partial x_{i}}=0 \\
\frac{\partial \bar{u}_{i}}{\partial t}+\frac{\partial}{\partial x_{j}} \bar{u}_{i} \bar{u}_{j}=-\Delta P \delta_{i j}-\frac{\partial \bar{p}}{\partial x_{i}}-\frac{\partial \tau_{i j}}{\partial x_{j}}+v \frac{\partial^{2} \bar{u}_{i}}{\partial x_{i} \partial x_{j}}
\end{gathered}
$$

where $\bar{u}_{i}$ is the velocity component in the i-direction, $\Delta \mathrm{P}$ the kinematic pressure gradient, $\delta_{i j}$ the Kronecker delta and $v$ the kinematic viscosity. The SGS Reynold stresses are modelled in the form:

$$
\tau_{i j}=-2 v_{S G S} S_{i j}
$$

where, $v_{S G S}$ denotes the SGS viscosity that, in OpenFOAM 2.3.x, is defined by:

$$
v_{S G S}=C_{\mathbb{R}} \Delta \sqrt{K}
$$

where $C_{k}=0.094, \Delta$ is the filter width taken to be the power average of grid sizes in all directions $\Delta=\left(\Delta_{1} \Delta_{2} \Delta_{2}\right)^{1 / a}$ and the SGS kinetic energy $\mathrm{K}$ is computed as:

$$
K=\frac{2 C_{K}}{C_{\theta}} \Delta^{2}|S|^{2}
$$


The computational domain consists of three identical idealised street canyons, perpendicularly disposed respect to the wind direction. Domain size results in a $3\left(W_{B}+W_{C}\right)$ length in the streamwise direction, where $W_{B}$ and $\mathrm{W}_{\mathrm{C}}$ are respectively the variable building and canyon widths. The building size is equal to $9 \mathrm{H}$ in the spanwise direction. Employing cyclic boundary conditions at the streamwise and spanwise faces of the domain, allows us to reproduce series of canyons of indefinite longitudinal length, i.e. an idealised two-dimensional canopy. The height of the computational domain is $9 \mathrm{H}$, larger than the minimum requested in the best practice guidelines (Tominaga et al., 2008; Franke et al., 2011; Blocken, 2015). A schematic representation is reported in Fig.1. The domain size in the streamwise direction ( $x$ axis), measured in building height units $(\mathrm{H})$, ranges from $3 \mathrm{H}$ to $9 \mathrm{H}$, depending on the building aspect ratio. A structured mesh with grid stretching both in streamwise and vertical direction was employed. In order to guarantee a high enough resolution near the buildings walls, the domain was discretized with 32 cells per $\mathrm{H}$. An expansion ratio lower than 1.2 was used for both the horizontal and vertical axes ( $x$ and $z$, respectively), according to the guidelines (Tominaga et al., 2008; Franke et al., 2011; Blocken, 2015). Therefore, the resolution is $\Delta \mathrm{x}=\Delta \mathrm{z}=0.016 \mathrm{H}$ in the proximity of the building walls and the ground, whist in the canyon centre the cell size is doubled. As a consequence, the total number of cells ranges from a minimum of $2.7 \cdot 10^{6}$ (in the case of $\mathrm{AR}_{\mathrm{B}}=0.5$ and $\mathrm{AR}_{\mathrm{C}}=0.5$ ) up to a maximum of $9.26 \cdot 10^{6}$ (in the case of $A R_{B}=2.0$ and $A R_{C}=1.0$ ). On the top we used the symmetry condition while to model the near-wall flows, the law due to Spalding, (1962) was applied both on the ground and in the building walls. All LES runs were initialized by means of a RANS solution (de Villiers E., 2006), and data used for computing statistics were collected after a sufficient interval of time for the complete development of turbulence. Namely, we chose a transitional time equal to 35 convective times, $\mathrm{T}_{\mathrm{C}}=\mathrm{L} / \mathrm{U}_{\text {mean }},\left(\mathrm{T}_{\mathrm{C}}\right.$ is also known as the flow-through time), where $\mathrm{L}$ is the domain size in the streamwise direction (see Fig.1). An overall time of $70 \mathrm{~T}_{\mathrm{C}}$ was used to accumulate the dataset in order to compute the velocity statistics. During, that interval time, data were recorded every $0.05 \mathrm{~T}_{\mathrm{C}}$, i.e. a time lapse long enough to ensure a satisfying statistical independence of samples. The mean streamwise velocity was imposed to obtain a Reynolds number at the building height $\mathrm{Re}_{\mathrm{H}}=\mathrm{U}_{\mathrm{H}} \mathrm{H} / \mathrm{v}=7000$, i.e. higher than the minimum value (3400) suggested by Hoydysh et al. (1974) for the flow to be independent of the Reynolds number. The dimensional time-step increment was set in order to assure that the Courant number was always smaller than 0.6 at all grid nodes. The results were averaged both in time, over a minimum of 1350 time steps, and spatially in the spanwise direction in order to enhance the statistical robustness of the dataset. 
As regards numerical methods, the second-order-accurate schemes were used for the time and space derivatives. Namely, the backward differencing scheme in the time derivatives, and the central differencing scheme (Gaussian integration with linear interpolation) in the spatial derivatives. The large time-step transient solver for incompressible flow, was applied for the pressure-velocity coupling scheme, by means of the PIMPLE algorithm (merged PISO-SIMPLE). The preconditioned conjugate gradient (PCG) method was used to solve the linear equation system for $\bar{p}$ and the preconditioned bi-conjugate gradient (PbiCG) method for $\bar{u}$.

\subsection{Laboratory Experiments}

Numerical simulations were compared to experiments conducted in the closed-loop water channel of the Hydraulics Laboratory of the University of Cagliari. Measurements were performed in the boundary layer above a series of 20 identical prismatic obstacles, with square section $\left(A R_{B}=1.0\right)$. These covered the entire spanwise length of the channel in order to represent an idealised two-dimensional canopy. Moreover, measurements were carried out on a $17^{\text {th }}$ canyon ensuring that the generated roughness layer reached the equilibrium (i.e. Llaguno-Munitxa et al., 2017), so that it is representative of an ideal infinite series of buildings. Two building spacings were considered: $\mathrm{AR}_{\mathrm{C}}=0.5$ and $\mathrm{AR}_{\mathrm{C}}=1.0$. The water-channel was $8.0 \mathrm{~m}$ long and the cross section was $0.40 \mathrm{~m}$ wide and $0.50 \mathrm{~m}$ high. The array of obstacles, painted in matt black to avoid laser light reflections, were placed $4.0 \mathrm{~m}$ downstream from the head of the channel. To allow a complete evolution of the turbulence and to achieve a logarithmic velocity profile, a grid with a honeycomb structure was placed at the head of channel and a $3.0 \mathrm{~m}$ long series of panels with loose gravel (equivalent diameter: $0.01 \mathrm{~m}$ ) was set on the channel bottom. A sharpcrested weir at the end of the channel regulated the water depth to $0.4 \mathrm{~m}$. The incoming velocity profile was logarithmic up to $0.14 \mathrm{~m}$ (corresponding to $7 \mathrm{H}$ ), with a maximum velocity of $0.36 \mathrm{~m} / \mathrm{s}$, and it was found in good agreement with the data of Farell and Iyengar (1999). At the building height $(\mathrm{H})$, a Reynolds number $\mathrm{Re}_{\mathrm{H}}=\mathrm{UHH}_{\mathrm{H}} / \mathrm{v}=5000$ was obtained, condition that satisfied $\mathrm{Re}_{\mathrm{H}}>3400$ as suggested by Hoydysh et al. (1974). The vertical streamwise mid-plane of the channel was illuminated by a diode laser emitting green light (532 $\mathrm{nm}$ in wavelength), through an optical system consisting of a cylindrical lens and a mirror. A high-speed camera $(2240 \times 1760$ pixels resolution $)$ recorded images at a $310 \mathrm{~Hz}$ frequency. The images, $150 \mathrm{~mm}$ height and $117 \mathrm{~mm}$ width, with a spatial resolution about $150 \mathrm{px} / \mathrm{cm}$, were recorded in 40 sessions (1200 
images in a period of $3.9 \mathrm{~s}$ each, for a total of 48000 images) separated by a proper time interval that assures the statistical independence, in order to increase the statistical robustness of the velocity dataset. Velocity fields were evaluated by tracking neutrally buoyant particles (pine pollen $50 \mu \mathrm{m}$ in diameter) homogeneously dispersed in the flow through an image analysis technique called Feature Tracking Velocimetry. Image analysis techniques have the advantage, compared to the traditional techniques implementing physical point probes, to be non-intrusive and quasicontinuous in space, so giving access to the laboratory measurement of many quantities, such as concentration fields (Ferrari and Querzoli 2010, Ferrari and Querzoli 2015, Ferrari et al., 2018-a and 2018 -b), wave surface positions (Ferrari et al., 2016) and velocity fields (e.g. Badas and Querzoli 2011, Di Bernardino et al 2015 -a); see Ferrari (2017) for a review. The Feature Tracking Velocimetry technique, described in (Besalduch et al., 2013, 2014), is based on: (1) the identification of the particle images on the frames by means of the Harris corner detection algorithm (Harris and Stephens 1988); (2) the interrogation windows comparison, for which the windows are centred on the particles and comparisons are made by measuring the dissimilarity between the windows of successive frames; (3) the evaluation of the particles displacement between two successive frames is defined as the displacement minimizing the dissimilarity between interrogation windows. The dissimilarity was determined by the Lorentzian robust estimation (Falchi et al., 2006). Finally, the velocity is obtained as the ratio of the particle displacement to the time interval between frames. Other details and results about the water channel experiments are discussed in Garau et al., (2018) and in Ferrari et al., (2017).

\section{RESULTS}

\subsection{Validation}

We compared 5 vertical profiles $(\mathrm{x} / \mathrm{H}=-0.4,-0.25,0,0.25,0.4)$ using $1^{\text {st }}$ and $3^{\text {rd }}$ order of velocity statistics; however, for the sake of brevity, we here show only vertical profiles of the streamwise velocity (Fig. 2 A-C) and the velocity skewness factor (Fig. $3 \mathrm{~A}-\mathrm{C}$ ) at the canyon central point, $\mathrm{x} / \mathrm{H}=0$, and near the building walls at $\mathrm{x} / \mathrm{H}= \pm 0.4$. These quantities were made non dimensional by the Us velocity, which corresponds to the velocity averaged between $\mathrm{z} / \mathrm{H}=1.0$ and $\mathrm{z} / \mathrm{H}=1.5$. In addition to the present experimental data, whose set-up was above described, we compared the numerical results with both wind tunnel and LES data 
available in literature. All the considered works focused on a twodimensional street canyon with $\mathrm{AR}_{\mathrm{B}}=\mathrm{AR}_{\mathrm{C}}=1.0$ which is the most investigated in literature . The wind tunnel data by Brown et al., (2000) was realised with an array of seven rectangular blocks extended from wall-to-wall in the spanwise direction. These obstacles were immersed in a neutral atmospheric boundary layer twelve times high with respect to the building height, the latter perpendicularly disposed respect to the wind direction. A pulsed wire anemometry (PWA), was employed to measure within and near the buildings, with 1200 samples at each point to evaluate velocities, then the turbulent statistics were sampled. For what concerns numerical simulations, Cui et al., (2004) performed an idealised street canyon (CSV81 case) with medium-high mesh resolution $(0.3 \mathrm{~m}$ in $x$ direction and $0.5 \mathrm{~m}$ in $z$ direction), and by employing a revisited Regional Atmospheric Modelling System (RAMS), originally applied for mesoscale applications, with cyclic boundary conditions, the normal velocity set to zero at walls and the Smagorinsky eddy viscosity model $\left(\mathrm{C}_{S}=0.8-1.2\right.$ depending on the location in the street canyon). Comparing results with the wind tunnel data of Brown et al.(2000), the authors found some reasonable dissimilarity related to the limitation of the employed domain (one single canyon) and to the not refined mesh near roofs, where the higher instability occurs. Therefore, Cheng and Liu, (2011a) carried out LES by employing three canyons with a $30 \%$ coarser mesh resolution in $\mathrm{x}$ direction and $20 \%$ larger in $\mathrm{z}$ direction (particularly at roof level), with respect to the previous LES described. Periodic conditions at the streamwise and spanwise directions, free-slip boundaries at the top and no-slip at the walls were employed by the authors. The present numerical set up is more similar to the Cheng and Liu, (2011a) one, with a coarser mesh resolution (by 10\%). The present simulation outcomes are in overall good agreement for both the parameters, even if some differences are visible for the skewness factor at the near wall profiles (Fig. 3 A, C). A detailed description will be done later. The non-dimensional mean streamwise velocities well agree with all the other studies inside the canyon, by correctly reproducing the trends, with negative values in the deeper cavity part and the evolution of the shear layer at the rooftop, becoming smoother going downstream. However, present LES results underestimate all the considered values above $\mathrm{z} / \mathrm{H}=2$, while the Cheng and Liu, (2011a) data, is in better agreement with the experimental curves (labelled in figure as Lab). This might depend on the higher statistic robustness of laboratory experiments, compared to the numerical ones, that would require longer computational time in order to completely resolve the largest flow structures, located above the canopy. The skewness factor numerically obtained is in good agreement with the experimental data over the whole vertical range for the central profile (Fig. 
$3 \mathrm{~B})$. Below $\mathrm{z} / \mathrm{H}=2.0$, it matches also with the other data and between $\mathrm{z} / \mathrm{H}=0.8$ and 1.0 , the negative values are correctly reproduced. The most noticeable discrepancy was found at the near wall profiles $(\mathrm{x} / \mathrm{H}= \pm 0.4)$ : looking at Fig. 3 A, wind tunnel data seems not clearly identifying the peak, in case of Cui et al, (2004) it appears amplified while in water channel outcomes it is underestimated. Besides, a good agreement is visible between present and Cheng and Liu, (2011a) LES, apart for the upper profile. Similarly, the two LES series are comparable in Fig. 3 C. Differences might be referred to the difference in the mesh resolution and input parameters, in case of numerical set up, and to the limitation of the experimental techniques in the near wall flow (for example the reflection problem in the water channel visualisations). Therefore, it is convenient to remember the importance of employing a large amount of data for good high moment statistics. In order to quantitative estimate the differences through the discussed data, the standard deviation was computed for each profile (Table 1).

A qualitative comparison was also done for the configuration $\mathrm{AR}_{\mathrm{C}}=0.5$, $\mathrm{AR}_{\mathrm{B}}=1.0$, providing comparable results between the experimental one of Salizzoni (2006) and the LES of Zhong (2016) (that were carried out on two dimensional configurations by means of respectively an array of identical buildings, such as the water channel ones, and a singular street canyon with periodic boundary conditions), and the numerical counterpart. The field topology shows the typical structure with two main counterrotating vortexes identified also by other authors (Hoydysh and Dabberdt 1988; Hassan and Crowther 1998; Soulhac 2000, Kovar, 2002). The mean velocity magnitude obtained for $\mathrm{AR}_{\mathrm{C}}=0.5, \mathrm{AR}_{\mathrm{B}}=1.0$ presents the two vortex centres in $\mathrm{z} / \mathrm{H}=0.2, \mathrm{z} / \mathrm{H}=0.8$ and $\mathrm{x} / \mathrm{H}=0.05$, in good agreement with the literature results. Their shapes resemble the ones found in Salizzoni (2006), not only in the central part of the canyon, but also near the walls and corners, with the main velocities in the upper part of the field close to the leeward wall. Despite the set-up differences, maps of the mean velocity variance display similar shapes with the highest values drawing a tongue that comes into the canyon, close to the leeward wall, and similar values. The highest discrepancies in values are shown along the leeward wall at around $\mathrm{z} / \mathrm{H}=0.7$, where present LES seems to overestimate the vertical velocities with respect to the counterparts. On the contrary, at the interface, where the exchange occurs, they appear a little bit underestimated; this might be caused by the different mesh resolution and the walls boundary conditions employed in numerical set-up. Moreover, the local turbulence production is caused by the roof-level velocity gradient, strongly dependent on the domain height, namely increasing with decreasing domain top, as observed by other authors (i.e Cheng and Liu, 2011a). 


\subsection{Velocity field Statistics}

Streamlines of the mean velocity field and mean velocity magnitude, made non-dimensional by the free stream velocity in cases of $\mathrm{AR}_{\mathrm{B}}=1.0$ and $\mathrm{AR}_{\mathrm{C}}=0.5,1.0$ are respectively shown in Fig. $4 \mathrm{~A}$ and $\mathrm{B}$. Instead of a single main vortex (Fig. $4 \mathrm{~B}$ ) in the narrow canyon there are two counterrotating vortexes (Fig. 4 A), as a consequence of the height increase with respect to the canyon width. Differences at the pedestrian level are relevant: the narrow canyon gives lower velocity values, and this could represent a negative aspect for air quality. Looking at the vertical velocity component (Fig. 5 A-B), which drives the air exchange in case of 2D street canyons, it is possible to notice how the values are small not only in the deepest vortex, but also at the roof level. The regions with the highest intensities are wider in case of $\mathrm{AR}_{\mathrm{C}}=1.0$. It is important to remember that, especially in the skimming flow regime, the air exchange at the roof level is mainly controlled by the turbulent mixing with a notable effect of the building aspect ratio, $\mathrm{AR}_{\mathrm{B}}$, (i.e Soulhac, 2000), while the increasing canyon width promotes the turbulent mixing also below the roof top. Accordingly, the air exchange is less dependent on the flow at the roof level, as demonstrated in Badas et al., (2017). Turbulent quantities play a fundamental role in promoting the air exchange between the canyon and the overlaying flow, as stated by $\mathrm{Ng}$ and Liu (2014). Maps of the variance of the vertical velocity component, made non dimensional by the freestream velocity $\left\langle\mathrm{w}^{\prime 2}\right\rangle / \mathrm{U}^{2}$ ref and the non-dimensional vertical momentum flux, $<\mathrm{u}^{\prime} \mathrm{w}^{\prime}>/ \mathrm{U}^{2}$ ref, are presented respectively in Fig. 6 and 7. The canyon width variation significantly affects the variance of the vertical velocity: for the narrow canyon $\left(A R_{C}=0.5\right)$, the values are significantly higher than zero only on the top of the downstream wall, whilst for $\mathrm{AR}_{\mathrm{C}}=1.0$, a great amount of the canyon flow exhibits high turbulence levels, in agreement with what stated by other authors (e.g. Di Bernardino et al., 2015). Irrespective of the canyon width, the two cases show the same trend (this is well visible in Figure $9 \mathrm{C}, \mathrm{F}$ ), with the maximum achieved around $\mathrm{z} / \mathrm{H}=$ 1.15 , above the roof, because of the effect of the shear layer, which is generated from the upstream building corner. Vertical momentum flux is negative outside the canyon and positive for $\mathrm{z} / \mathrm{H}<0.8$ in both the cases. However, the values are smaller in the case of narrow canyon than in the wider one (Fig. 9 A) where the absolute maximum is approximately doubled. All these considerations converge and underline that narrow canyons are poor ventilated. Even if the differences observed between these two cases $\left(\mathrm{AR}_{\mathrm{C}}=0.5\right.$ and 1.0), are quite apparent, all the field maps representation, corresponding to different building aspect ratios, at a given canyon shape, do not exhibit significant qualitative differences. This can be noticed in the Fig. 8 which shows, as an example, the vertical velocity 
fields for three different $\mathrm{AR}_{\mathrm{B}}(0.5,1.0,1.5$ respectively in Fig. 8 A, B, C). It is evident that the flow topology and the regions of positive and negative vertical velocity are very similar both in magnitude and in extension.

As a matter of fact, with the aim to synthetically describe the effect due by the building aspect ratio on the flow, all the statistics have been horizontally averaged (Eq. 7), from the middle point of the upwind building to the middle point of the downwind one, by considering the full domain height:

$$
\overline{\gamma(z)}=\frac{1}{\lambda(z)} \int_{\lambda(\underline{\Omega})} y d x
$$

where $\gamma$ is the generic temporally averaged parameter, $z$ is the generic height and $\lambda(\mathrm{z})$ is the horizontal integration line. The length of $\lambda$ is dependent on the integration height: into the canyon it is equal to the canyon width; while above the canyon it corresponds to $\mathrm{AR}_{\mathrm{C}}+\mathrm{AR}_{\mathrm{B}}$. The resulting horizontally averaged profiles, made non-dimensional by the free-stream velocity at $\mathrm{z} / \mathrm{H}=9$, are displayed in Fig. 9. Focusing on the horizontal velocity profiles (Fig. 9 A, D), differences are more evident above the canopy where a quite regular increase of the mean velocity with the increase of the building width is shown for $\mathrm{AR}_{\mathrm{C}}=1.0$. Differently, in the case of $\mathrm{AR}_{\mathrm{C}}=0.5$, the profiles collapse in a unique trend, unless for $\mathrm{AR}_{\mathrm{B}}=2.0$, that gives larger values of the horizontal velocity above the building height. About the horizontally-averaged turbulent momentum flux (Fig. 9 B, E), the influence of $\mathrm{AR}_{\mathrm{B}}$ is mainly apparent outside of the canyon cavity. For $\mathrm{z} / \mathrm{H}>1$ the values are negative for all the analysed configurations. The curves present a maximum just above the roof, around the height $\mathrm{z} / \mathrm{H}=1.15$. The highest momentum fluxes among the studied cases are achieved in the case of $\mathrm{AR}_{\mathrm{B}}=0.5, \mathrm{AR}_{\mathrm{C}}=1.0$, which correspond to the smallest ratio of the building area to the canyon area. This is mainly caused by the higher vertical turbulent mixing, as confirmed by the variance profiles (Fig. $9 \mathrm{C}, \mathrm{F}$ ). The negative momentum flux is higher in all the cases with $A R_{C}=1.0$, irrespective of the studied $A R_{B}$. The variance of the vertical velocity component shows a significant increase of the turbulence not only above the roof, as a consequence of the canopy structure, but also into the canyon cavity. A systematic trend with the building width increase is not apparent: in the case $\mathrm{AR}_{\mathrm{C}}=0.5$ the maximum value is achieved for $\mathrm{AR}_{\mathrm{B}}=0.5$ between $\mathrm{z} / \mathrm{H}=0.5$ and $\mathrm{z} / \mathrm{H}=$ 1.0, whilst for greater heights it moves closer to the cases $A_{B}=1.0,1.5$. The behaviour of $\mathrm{AR}_{\mathrm{B}}=2.0$ differs from the others above the cavity, where the maximum value is achieved around $\mathrm{z} / \mathrm{H}=1.4$. In the case of $A R_{C}=1.0$ for both the $A_{B}=0.5,1.0$, the vertical variance level is higher 
for the whole canyon depth, than in the other two configurations, which exhibit a similar trend. Outside of the canyon, the smallest aspect ratio configuration achieves the maximum around $\mathrm{z} / \mathrm{H}=1.4$.

In summary, present results suggest that the increase of building aspect ratio drives lower interaction between the canyon internal flow and the overlaying boundary layer, and this behaviour is more pronounced for the smallest canyon aspect ratio.

\subsection{Flux Exchange Index}

As already stated in the previous sections, the bulk air exchange between the canyon and the external boundary layer occurs at the interfacial surface i.e. at the roof level and, under the ideal case of a well-mixed box where the pollutant concentration is assumed to be constant within the canyon,(Fackrell, 1984; Vincent, 1977; Weitbrecht et al., 2008), the outflow rate on the top would be sufficient to describe the phenomenon. The averaged concentration within the canyon in fact, was found to be strongly dependent on the interaction between the recirculating flow and the incoming flow at the interface (i.e. Soulhac et al., 2008; Salizzoni, 2006). However, in the complex real world, the pollutant concentration may vary significantly with height. Therefore, it is useful to give a more detailed description of the phenomenon. In order to better understand the air exchange capability at different heights of the canyon, we estimated $\varphi_{e}(\mathrm{z})$, i.e. the outflow rate per spanwise unit length across a generic horizontal section of the canyon at height $\mathrm{z}$ :

$$
\varphi_{\theta}(z)=\frac{1}{2} \overline{\int_{W}|w(t)| d x}
$$

In addition, we evaluated the contribution of the mean velocity, $\varphi_{e m}$, according to the equation:

$$
\varphi_{e m}(z)=\frac{1}{2} \int_{W}|\bar{w}| d x
$$

The flux exchange index formulation has been wider dealt with in Garau et al., (2018). Vertical profiles of $\varphi_{e}(\mathrm{z})$ and $\varphi_{e m}(\mathrm{z})$ were computed by integrating respectively the instantaneous and mean velocity fields, over 32 horizontal lines connecting the canyon sidewalls. Results are displayed in Fig. $10 \mathrm{~A}$ and $\mathrm{B}$ for canyon $\mathrm{W}=0.5 \mathrm{H}$ and $1.0 \mathrm{H}$, respectively. The two series of data, both for $\varphi_{e}$, (solid lines) and $\varphi_{e m}$ (dashed lines), show completely different trends according to the different topology of the flow. For $\mathrm{AR}_{\mathrm{C}}=0.5$, the contribution of the mean flow is close to the total 
outflow rate, indicating a relatively small contribution of the turbulence for $\mathrm{z} / \mathrm{H}>0.5$. As a matter of fact, the contribution of the turbulence is significant only at the interfacial layer at the rooftop level. $\varphi_{\text {em }}$ exhibits a maximum at $\mathrm{z} / \mathrm{H} \approx 0.75$, corresponding to the maximum mean vertical velocity induced by the upper vortex. For $\mathrm{z} / \mathrm{H}<0.5$ the lower vortex generates only a weak vertical air exchange, and the contribution of the turbulence is predominant. However, in that region, the overall outflow rate is meaningfully smaller compared to the region corresponding to the upper vortex, confirming a poor air ventilation in narrow canyons, especially at the pedestrian level. Analysing the case $\mathrm{AR}_{\mathrm{C}}=1.0$ (Fig. 10 B), all configurations have similar trends with the maximum at about $\mathrm{z} / \mathrm{H}$ $=0.5$, that is the level corresponding to the centre of the dominant vortex into the canyon. Total outflow only slightly exceeds the contribution of the mean flow at all levels but the interfacial layer at the rooftop, where the contribution of the turbulent mixing is relatively high.

Both these scenarios are highly influenced by the building aspect ratio. Indeed, a distinct dependence of the outflow rate on $\mathrm{AR}_{\mathrm{B}}$ is observed for the configurations $\mathrm{AR}_{\mathrm{C}}=1.0, \mathrm{AR}_{\mathrm{B}}=0.5$. Differences are more appreciable at the maximum point and at the roof level. At the height of the relative maximum, $\mathrm{AR}_{\mathrm{B}}=2.0$ yields the maximum value in the narrow canyon, whereas the maximum is attained for $\mathrm{AR}_{\mathrm{B}}=0.5$ in the square section canyon. Differently, at the roof level, the maximum air exchange index is given by $\mathrm{AR}_{\mathrm{B}}=0.5$ irrespective of the canyon aspect ratio. Anyway, we need to underline that reality is far more complex than this simplified set-up. Thus, for example, the shear layer generated from lateral openings and motions related to the corner vortex mechanism, which are here neglected, play a fundamental role in driving air exchange (i.e. Nosek et al., 2018). In addition to this, the adopted model can be considered valid only in case of uniform pollutant distribution inside the canyon, because of both the convective and total pollutant exchange mechanisms strongly depend on source locations (e.g. Kubilay et al., 2016). Moreover, here we only consider the case of a neutral boundary layer, while conditions can be further complex in case of unstable and convective boundary layers, where more complex spatial structures may arise also in case of flat terrain (Badas and Querzoli, 2011), and non-local mixing should be properly considered

All the aforementioned factors may have a different impact depending on the building aspect ratio variations so that a comprehensive focus on this issue could be evaluated in future works.

The total outflow rate and the contribution of the mean flow at the roof level as a function of the building aspect ratio, for both the cases $A R_{C}=$ 0.5 and $\mathrm{AR}_{\mathrm{C}}=1.0$ are shown in Fig. 11. As can be expected, the canyon with unit aspect ratio gives the highest exchange rates irrespective of the 
building aspect ratio. However, for both $\mathrm{AR}_{\mathrm{C}}=0.5$ and $\mathrm{AR}_{\mathrm{C}}=1.0, \varphi_{\mathrm{e}}$ is not monotonic and exhibits a relative minimum at $\mathrm{AR}_{\mathrm{B}}=1.5$.

We also evaluated the mean residence time $T_{r}$ as a function of the building aspect ratio. This parameter controls the dynamics of pollutant removal, usually derived by the pollutant release (e.g. Kubilay et al., 2017). However, by using the well mixed box model and by assuming a uniform pollutant distribution inside the canyon, the residence time was here estimated employing the Eq. 10 (Garau et al., 2018), where the volume may be rewritten as $V_{c}=S_{c} \times L$ ( $S_{c}$ is the cross-sectional area and $L$ is the cross-stream length of the canyon):

$$
T_{r}=\frac{V_{C}}{L * \varphi_{e(z=H)}}=\frac{S_{C}}{\varphi_{e(z=H)}}
$$

Fig. 12 shows the residence time, made non-dimensional by the building height and the free-stream velocity. $T_{r}$, linearly increases with $\mathrm{AR}_{\mathrm{B}}$ up to $\mathrm{AR}_{\mathrm{B}}=1.5$, for both the analysed street-canyon aspect ratio. That value, in the case of $\mathrm{AR}_{\mathrm{C}}=0.5$, represents the maximum (in agreement with the behaviour of the outflow rate shown in Fig. 11), and, beyond that, $T_{r}$, remains nearly constant Irrespective of the canyon aspect ratio, the shape of the building plays a key role in the street ventilation. As a matter of fact, in the investigated range of $\mathrm{AR}_{\mathrm{B}}, T_{r}$ shows an increment around $75 \%$ for $\mathrm{AR}_{\mathrm{C}}=0.5$ and $28 \%$ for $\mathrm{AR}_{\mathrm{C}}=1.0$.

\section{CONCLUSIONS}

We investigated the effect of building aspect ratio on street canyon ventilation and turbulent flow characteristics by means of LES numerical model. We analysed the flow above an urban canopy consisting of a virtually infinite series of two-dimensional canyons with rectangular cross section. Two different canyon aspect ratios $\left(\mathrm{AR}_{\mathrm{C}}=0.5,1.0\right)$, and four building aspect ratios, i.e. $\mathrm{AR}_{\mathrm{B}}=0.5,1.0,1.5$ and 2.0 were considered. LES results were successfully validated against our experimental results obtained in a laboratory water channel, and other literature available data. Data was analysed in terms of the mean and the turbulent quantities, outflow rate and residence time. Results point out a different effect of the building aspect ratio on the studied quantities with respect to the canyon aspect ratio. For $\mathrm{AR}_{\mathrm{C}}=0.5$, the highest turbulence levels and momentum fluxes were observed in the roughness sub-layer when $\mathrm{AR}_{\mathrm{B}}=2.0$, while for $\mathrm{AR}_{\mathrm{C}}=1.0$ it was observed in case of $\mathrm{AR}_{\mathrm{B}}=0.5$. Correspondingly, these cases also promote the maximum exchange rates within the canyon. 
The analysis of the flow exchange rates between the canyon and the overlaying boundary layer highlights that the flow-rate increases for narrow buildings. However, a minimum exchange rate was observed for $\mathrm{AR}_{\mathrm{B}}=1.5$, irrespective of the canyon shape. Finally, the residence time is linearly proportional to the building aspect ratio for the whole extent of the investigated rate, in the case of $\mathrm{AR}_{\mathrm{C}}=1.0$, and up to $\mathrm{AR}_{\mathrm{B}}=1.5$ for the case $A R_{C}=0.5$. Results suggest that the building aspect ratio is a crucial parameter when predicting pollutant removal from urban canyons and in the modelling of the urban boundary layer characteristics.

\section{REFERENCES}

Badas, M.G., Querzoli, G, 2011. Spatial structures and scaling in the Convective Boundary Layer (2011) Experiments in Fluids, 50 (4), pp. 1093-1107. DOI: 10.1007/s00348-010-1020-z

Badas, M.G., Ferrari, S., Garau, M., Querzoli, G., 2017. On the effect of gable roof on natural ventilation in two-dimensional urban canyons. J. Wind Eng. Ind. Aerodyn. 162, 24-34. https://doi.org/10.1016/j.jweia.2017.01.006

Badas, M.G., Garau, M., Seoni, A., Ferrari, S., Querzoli, G., 2018 -a. Impact of rooftop stack configuration on 2D street canyon air quality. J. Phys. Conf. Ser. 1110, 012003. https://doi.org/10.1088/1742-6596/1110/1/012003

Badas, M.G., Salvadori, L., Garau. M., Querzoli, G. and Ferrari, S., 2018 -b. Urban areas parameterisation for CFD simulation and cities air quality analysis, Int. J. Environment and Pollution (in press)

Bernardino, A.D., Monti, P., Leuzzi, G., Sammartino, F., Ferrari, S., 2017. Experimental investigation of turbulence and dispersion around an isolated cubic building. HARMO 2017 - 18th International Conference on Harmonisation within Atmospheric Dispersion Modelling for Regulatory Purposes, Proceedings, 2017October, pp. 460-464

Besalduch, L.A., Badas, M.G., Ferrari, S., Querzoli, G., 2014. On the near field behavior of inclined negatively buoyant jets. EPJ Web Conf. 67, 02007. https://doi.org/10.1051/epjconf/20146702007

Besalduch, L.A., Badas, M.G., Ferrari, S., Querzoli, G., 2013. Experimental Studies for the characterization of the mixing processes in negative buoyant jets. EPJ Web Conf. 45, 01012. https://doi.org/10.1051/epjconf/20134501012

Blocken, B., 2015. Computational Fluid Dynamics for urban physics: Importance, scales, possibilities, limitations and ten tips and tricks towards accurate and reliable simulations. Build. Environ., Fifty Year Anniversary for Building and Environment 91, 219-245. https://doi.org/10.1016/j.buildenv.2015.02.015

Brown, M.J., Lawson, R.E., Decroix, D.S., Lee, R.L., 2000. Mean Flow and Turbulence Measurements Around a 2-D Array of Buildings in a Wind Tunnel [WWW Document]. URL http://permalink.lanl.gov/object/tr?what=info:lanlrepo/lareport/LA-UR-99-5395 (accessed 6.19.17).

Castro, I.P., Robins, A.G., 1977. The flow around a surface-mounted cube in uniform and turbulent streams. J. Fluid Mech. 79, 307-335. https://doi.org/10.1017/S0022112077000172

Chan, A.T., Au, W.T.W., So, E.S.P., 2003. Strategic guidelines for street canyon geometry to achieve sustainable street air quality - part II: multiple canopies and 
canyons. Atmos. Environ. 37, 2761-2772. https://doi.org/10.1016/S13522310(03)00252-8

Cheng, W.C., Liu, C.-H., 2011a. Large-Eddy Simulation of Flow and Pollutant Transports in and Above Two-Dimensional Idealized Street Canyons. Bound.Layer Meteorol. 139, 411-437. https://doi.org/10.1007/s10546-010-9584-y

Cheng, W.C., Liu, C.-H., 2011b. Large-Eddy Simulation of Flow and Pollutant Transports in and Above Two-Dimensional Idealized Street Canyons. Bound.Layer Meteorol. 139, 411-437. https://doi.org/10.1007/s10546-010-9584-y

Chung, T.N.H., Liu, C.-H., 2012. Large-eddy simulation of reactive pollutant dispersion for the spatial instability of photo stationary state over idealised 2D urban street canyons. Int. J. Environ. Pollut. 50, 411-419. https://doi.org/10.1504/IJEP.2012.051211

Cui, Z., Cai, X., J. Baker, C., 2004. Large-eddy simulation of turbulent flow in a street canyon. Q. J. R. Meteorol. Soc. 130, 1373-1394. https://doi.org/10.1256/qj.02.150

de Villiers, E., n.d. The Potential of Large Eddy Simulation for the Modeling of Wall Bounded Flows 375.

Di Bernardino, A., Monti, P., Leuzzi, G., Querzoli, G., 2015 -a. On the effect of the aspect ratio on flow and turbulence over a two-dimensional street canyon. Int. J. Environ. Pollut. 58, 27-38. https://doi.org/10.1504/IJEP.2015.076581

Di Bernardino, A., Monti, P., Leuzzi, G., Querzoli, G., 2015 -b. Water-Channel Study of Flow and Turbulence Past a Two-Dimensional Array of Obstacles. Bound.-Layer Meteorol. 155, 73-85. https://doi.org/10.1007/s10546-014-9987-2

Fackrell, J.E., 1984b. Parameters characterising dispersion in the near wake of buildings. Journal of Wind Engineering and Industrial Aerodynamics 16, 97-118. https://doi.org/10.1016/0167-6105(84)90051-5

Farell, C., Iyengar, A.K.S., 1999. Experiments on the wind tunnel simulation of atmospheric boundary layers. J. Wind Eng. Ind. Aerodyn. 79, 11-35. https://doi.org/10.1016/S0167-6105(98)00117-2

Falchi M., Querzoli G., Romano G.P., 2006. Robust evaluation of the dissimilarity between interrogation windows in image velocimetry, Experiments in Fluids, 41 (2), 279-293

Ferrari S. and Querzoli G., 2010: Mixing and re-entrainment in a negatively buoyant jet. J Hydraul Res, 48, 632-640, DOI: 10.1080/00221686.2010.512778

Ferrari S. and Querzoli G., 2015: Laboratory experiments on the interaction between inclined negatively buoyant jets and regular waves. Eur Phys J WoC, 92, 02018, DOI: 10.1051/epjconf/20159202018

Ferrari, S., Badas, M.G. and Querzoli, G., 2016 -a. A non-intrusive and continuous-inspace technique to investigate the wave transformation and breaking over a breakwater, Eur. Phys. J. WoC, Vol. 114, Article No. 02022, DOI: 10.1051/epjconf/201611402022

Ferrari, S., Badas, M.G., Garau, M., Seoni, A., Querzoli, G.,2016 -b. The air quality in two-dimensional urban canyons with gable roof buildings: A numerical and laboratory investigation. HARMO 2016 - 17th International Conference on Harmonisation within Atmospheric Dispersion Modelling for Regulatory Purposes, Proceedings, 2016-May, pp. 351-356

Ferrari, S., Badas, M.G., Garau, M., Querzoli, G., Seoni, A., 2017. The air quality in narrow two-dimensional urban canyons with pitched and flat roof buildings. Int. J. Environ. Pollut. 62, 347-368, DOI: 10.1504/IJEP.2017.089419

Ferrari, S. 2017. Image analysis techniques for the study of turbulent flows. EPJ Web of Conferences, 143, art. no. 01001, DOI: 10.1051/epjconf/201714301001 
Author

Ferrari, S., Badas, M.G., Querzoli, G., 2018 -a. On the effect of regular waves on inclined negatively buoyant jets. Water (Switzerland), 10 (6), art. no. 726, DOI: 10.3390/w10060726

Ferrari, S., Badas, M.G., Querzoli, G., 2018 -b. An Investigation on the Effects of Different Stratifications on Negatively Buoyant Jets. EPJ Web of Conferences, 180, art. no. 02025, DOI: 10.1051/epjconf/201818002025

Franke, J., Hellsten, A., Schlunzen, K.H., Carissimo, B., 2011. The COST 732 Best Practice Guideline for CFD simulation of flows in the urban environment: a summary. Int. J. Environ. Pollut. 44, 419-427. https://doi.org/10.1504/IJEP.2011.038443

Garau, M., Grazia Badas, M., Ferrari, S., Seoni, A., Querzoli, G., 2017. The air quality in urban canyons with tight and wide buildings. HARMO 2017 - 18th International Conference on Harmonisation within Atmospheric Dispersion Modelling for Regulatory Purposes, Proceedings, 2017-October, pp. 470-474

Garau, M., Badas, M.G., Ferrari, S., Seoni, A., Querzoli, G., 2018. Turbulence and Air Exchange in a Two-Dimensional Urban Street Canyon Between Gable Roof Buildings. Bound. Layer Meteorol. 1-21. https://doi.org/10.1007/s10546-0170324-4

Hang, J., Li, Y., 2011. Age of air and air exchange efficiency in high-rise urban areas and its link to pollutant dilution. Atmos. Environ. 45, 5572-5585. https://doi.org/10.1016/j.atmosenv.2011.04.051

Harris C., Stephens M.,1988. A combined corner and edge detector. In: Alvey vision conference. Citeseer, pp 10-5244

Hassan AA., Crowther JM., 1998. Modelling of fluid flow and pollutant dispersion in a street canyon. Environ Monit Assess 52(1-2):281-297

Hoydysh WG., Dabberdt WF., 1988. Kinematics and dispersion characteristics of flows in asymetric street canyons. Atmos Environ 22(12):2677-2689

Hoydysh, W.G., Griffiths, R.A., Ogawa, Y., 1974. A scale model study of the dispersion of pollution in street canyon. APCA Paper, APCA Paper 74-157. https://doi.org/Presented at the 67th APCA Annual Meeting

Kanda, M., 2006. Large-Eddy Simulations on the Effects of Surface Geometry of Building Arrays on Turbulent Organized Structures. Bound.-Layer Meteorol. 118, 151-168. https://doi.org/10.1007/s10546-005-5294-2

Kovar, A., 2002. Influence of geometry on the mean flow within urban street canyons - a comparison of wind tunnel experiments and numerical simulations. URL http://www.eng.uwo.ca/people/esavory/cavitygeometry.pdf .

Kubilay, A., Neophytou, M.K.-A., Matsentides, S., Loizou, M., Carmeliet, J., 2017. The Pollutant Removal Capacity of an Urban Street Canyon and its Link to the Breathability and Exchange Velocity. Procedia Engineering, International HighPerformance Built Environment Conference - A Sustainable Built Environment Conference 2016 Series (SBE16), iHBE 2016 180, 443-451. https://doi.org/10.1016/j.proeng.2017.04.203

Li, X.-X., Liu, C.-H., Leung, D.Y.C., 2008. Large-Eddy Simulation of Flow and Pollutant Dispersion in High-Aspect-Ratio Urban Street Canyons with Wall Model. Bound.-Layer Meteorol. 129, 249-268. https://doi.org/10.1007/s10546008-9313-y

Llaguno-Munitxa, M., Bou-Zeid, E., Hultmark, M., 2017. The influence of building geometry on street canyon air flow: Validation of large eddy simulations against wind tunnel experiments. Journal of Wind Engineering and Industrial Aerodynamics 165, 115-130. https://doi.org/10.1016/j.jweia.2017.03.007 
Martinuzzi, R., Tropea, C., 1993. The Flow Around Surface-Mounted, Prismatic Obstacles Placed in a Fully Developed Channel Flow (Data Bank Contribution). J. Fluids Eng. 115, 85-92. https://doi.org/10.1115/1.2910118

Millward-Hopkins, J.T., Tomlin, A.S., Ma, L., Ingham, D., Pourkashanian, M., 2011. Estimating Aerodynamic Parameters of Urban-Like Surfaces with Heterogeneous Building Heights. Bound.-Layer Meteorol. 141, 443-465. https://doi.org/10.1007/s10546-011-9640-2

Neophytou, M.K.-A., Markides, C.N., Fokaides, P.A., 2014. An experimental study of the flow through and over two dimensional rectangular roughness elements: Deductions for urban boundary layer parameterizations and exchange processes. Phys. Fluids 26, 086603. https://doi.org/10.1063/1.4892979

Nosek, Š., Fuka, V., Kukačka, L., Kluková, Z., Jaňour, Z., 2018. Street-canyon pollution with respect to urban-array complexity: The role of lateral and mean pollution fluxes. Building and Environment 138, 221-234. https://doi.org/10.1016/j.buildenv.2018.04.036

Ng, C.-T., Liu, C.-H., 2014. Numerical simulations of street canyon ventilation and pollutant dispersion. Int. J. Environ. Pollut. 55, 167-173. https://doi.org/10.1504/IJEP.2014.065921

Oke, T.R., 1988. Street design and urban canopy layer climate. Energy Build. 11, 103 113. https://doi.org/10.1016/0378-7788(88)90026-6

Pope, S.B., 2000. Turbulent Flows. Cambridge University Press. ISBN: 0521598869

Ricci, A., Kalkman, I., Blocken, B., Burlando, M., Freda, A., Repetto, M.P., 2017. Localscale forcing effects on wind flows in an urban environment: Impact of geometrical simplifications. J. Wind Eng. Ind. Aerodyn. 170, 238-255. https://doi.org/10.1016/j.jweia.2017.08.001

Salizzoni P.,2006. Mass and momentum transfer in the urban boundary layer. $\mathrm{PhD}$ thesis, Politecnico di Torino-Ecole Centrale de Lyon, 186 pp

Smagorinsky, J., 1963. General circulation experiments with the primitive equations. Mon. Weather Rev. 91, 99-164. https://doi.org/10.1175/15200493(1963)091<0099:GCEWTP>2.3.CO;2

Soulhac L., 2000 Modélisation de la dispersion atmosphérique à l'intérieur de la canopée urbaine. PhD thesis, École Centrale de Lyon, 345 pp

Soulhac, L., Perkins, R.J., Salizzoni, P., 2008. Flow in a Street Canyon for any External Wind Direction. Boundary-Layer Meteorology 126, 365-388. https://doi.org/10.1007/s10546-007-9238-x

Spalding, D.B., 1962. A new analytical expression for the drag of a flat plate valid for both the turbulent and laminar regimes. Int. J. Heat Mass Transf. 5, 1133-1138. https://doi.org/10.1016/0017-9310(62)90189-8

Tominaga, Y., Mochida, A., Yoshie, R., Kataoka, H., Nozu, T., Yoshikawa, M., Shirasawa, T., 2008. AIJ guidelines for practical applications of CFD to pedestrian wind environment around buildings. J. Wind Eng. Ind. Aerodyn., 4th International Symposium on Computational Wind Engineering (CWE2006) 96, 1749-1761. https://doi.org/10.1016/j.jweia.2008.02.058

van Hooff, T., Blocken, B., 2010. Coupled urban wind flow and indoor natural ventilation modelling on a high-resolution grid: A case study for the Amsterdam ArenA stadium. Environ. Model. Softw. 25, 51-65. https://doi.org/10.1016/j.envsoft.2009.07.008

Vincent, J.H., 1977. Model experiments on the nature of air pollution transport near buildings. Atmospheric Environment (1967) 11, 765-774. https://doi.org/10.1016/0004-6981(77)90186-X 
Author

Weitbrecht, V., Socolofsky, S.A., Jirka, G.H., 2008. Experiments on Mass Exchange between Groin Fields and Main Stream in Rivers. Journal of Hydraulic Engineering 134, 173-183. https://doi.org/10.1061/(ASCE)07339429(2008) 134:2(173)

Wong, C.C.C., Liu, C.-H., 2012. Pollutant dispersion over two-dimensional idealised urban roughness: a large-eddy simulation approach. Int. J. Environ. Pollut. 50, 6474. https://doi.org/10.1504/IJEP.2012.051181

Zaki, S.A., Hagishima, A., Tanimoto, J., Ikegaya, N., 2011. Aerodynamic Parameters of Urban Building Arrays with Random Geometries. Bound.-Layer Meteorol. 138, 99-120. https://doi.org/10.1007/s10546-010-9551-7

Zhong, J., 2016. Modelling air pollution within a street canyon (d_ph). University of Birmingham. 


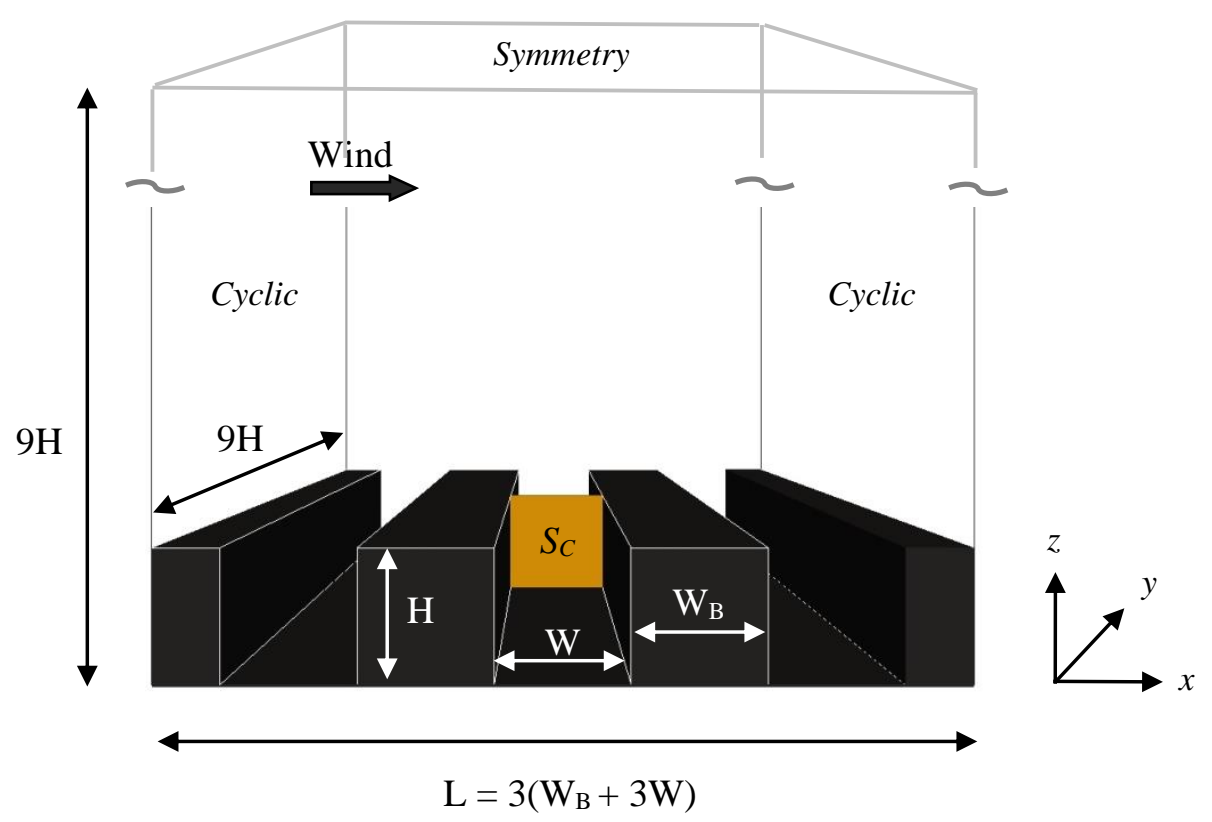

Figure 1. Schematic representation of domain and boundary conditions. H: building height; $\mathrm{W}_{\mathrm{B}}$ : building width; $W$ : canyon width; $S_{c}$ : cross-section of the canyon (shaded in yellow). Domain sizes are: $\mathrm{x}$-direction: dependent on $\mathrm{W}$ and $\mathrm{W}_{\mathrm{B}}$ sizes; $\mathrm{z}$-direction $=9 \mathrm{H}$; y-direction: $9 \mathrm{H}$
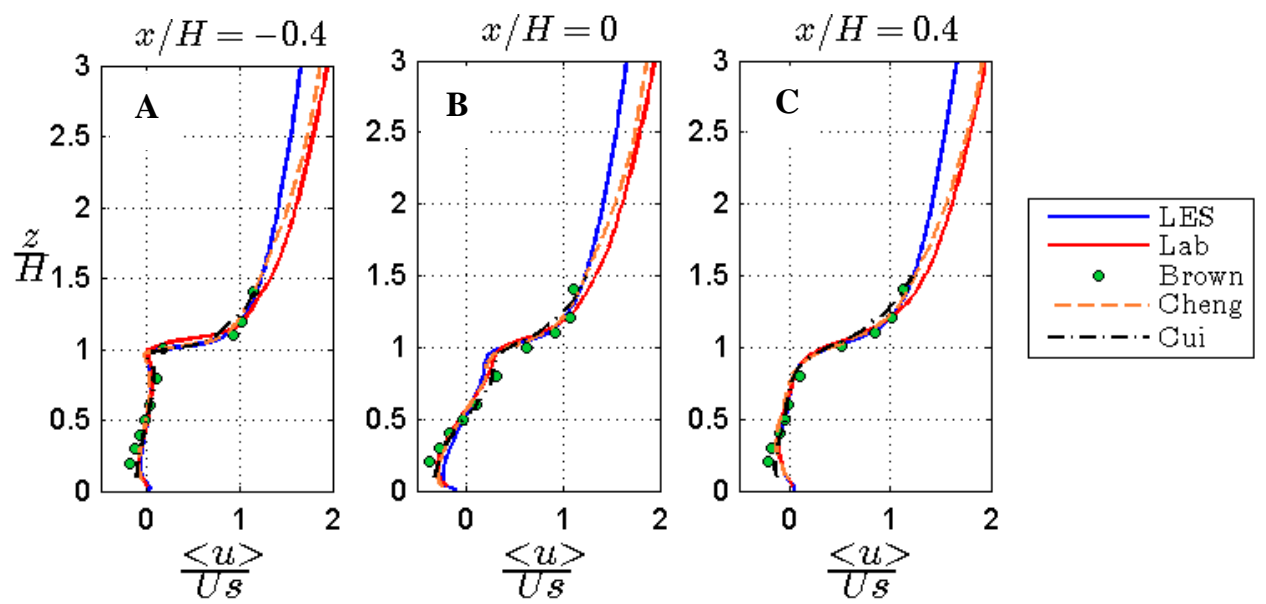

Figure 2. Vertical profiles of the streamwise velocity for $\mathrm{x} / \mathrm{H}=-0.4(\mathrm{~A}), \mathrm{x} / \mathrm{H}=0.0$ (B) and $\mathrm{x} / \mathrm{H}=0.4(\mathrm{C})$, made non dimensional by Us (velocity averaged for $1<\mathrm{z} / \mathrm{H}<1.5$ ). Building aspect ratio $\mathrm{AR}_{\mathrm{B}}=1.0$. Canyon aspect ratio, $\mathrm{AR}_{\mathrm{C}}=0.5$. Solid blue line: present numerical simulations, solid red line: our experimental results, dashed orange line: numerical simulations from Cheng and Liu (2011), dashed black line: numerical results from Cui et al. (2004), green circles: experimental results from Brown et al. (2000). 

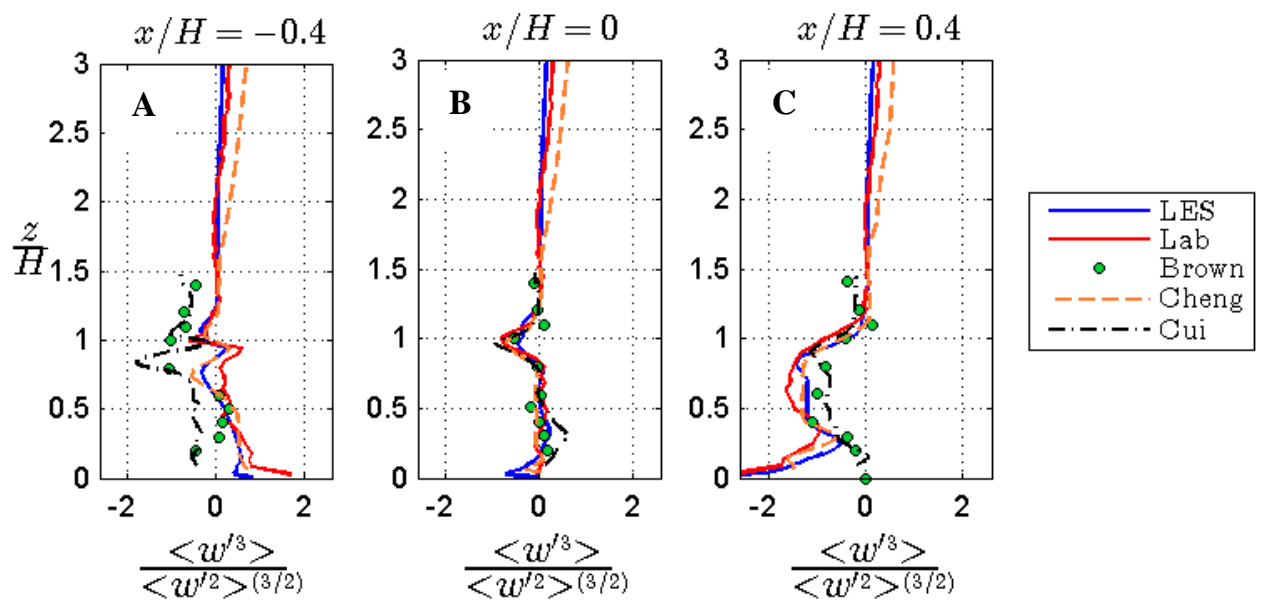

Figure 3. Vertical profiles of the vertical skewness factor for $\mathrm{x} / \mathrm{H}=-0.4(\mathrm{~A}), \mathrm{x} / \mathrm{H}=0$ (B) and $\mathrm{x} / \mathrm{H}=0.4(\mathrm{C})$, made non dimensional by Us (velocity averaged for $1<\mathrm{z} / \mathrm{H}<1.5$ ). Building aspect ratio $\mathrm{AR}_{\mathrm{B}}=1.0$. Canyon aspect ratio, $\mathrm{AR}_{\mathrm{C}}=0.5$. Solid blue line: present numerical simulations, solid red line: experimental results, dashed orange line: numerical simulations from Cheng and Liu (2011), dashed black line: numerical results from Cui et al. (2004), green circles: experimental results from Brown et al. (2000).
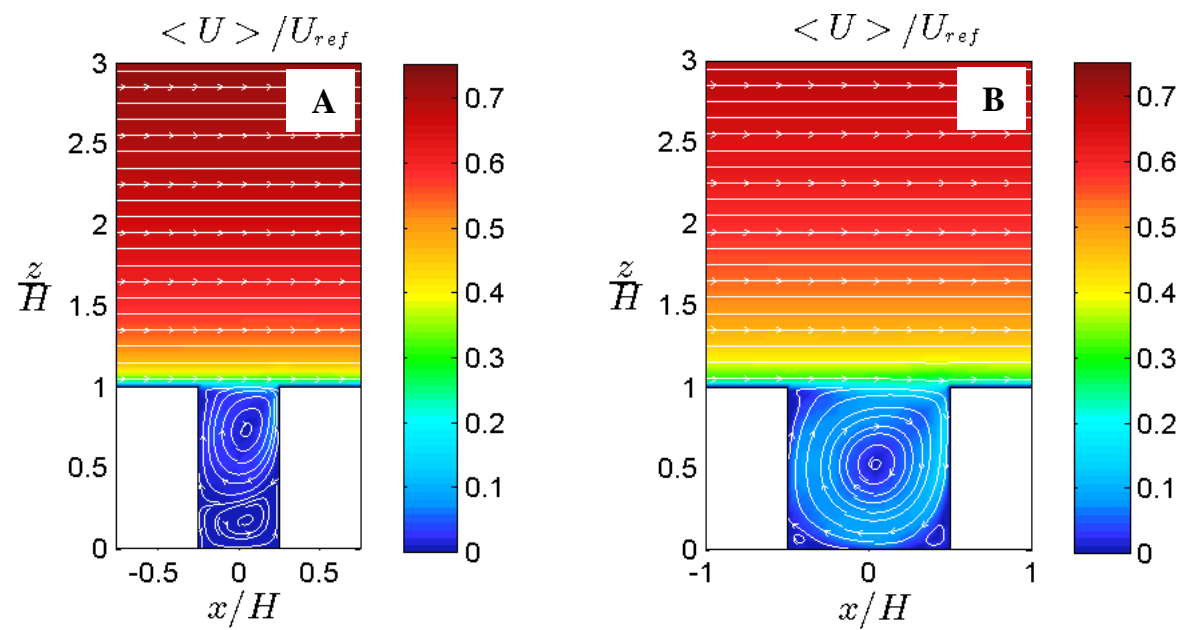

Figure 4. Streamlines of the mean velocity field and mean velocity magnitude, made non-dimensional by the freestream velocity $\left(U_{\text {ref }}\right.$ at $\left.\mathrm{z} / \mathrm{H}=9\right)$. Building aspect ratio $\mathrm{AR}_{\mathrm{B}}=$ 1. Canyon aspect ratio, $\mathrm{AR}_{\mathrm{C}}=0.5(\mathrm{~A})$ and $\mathrm{AR}_{\mathrm{C}}=1(\mathrm{~B})$. 

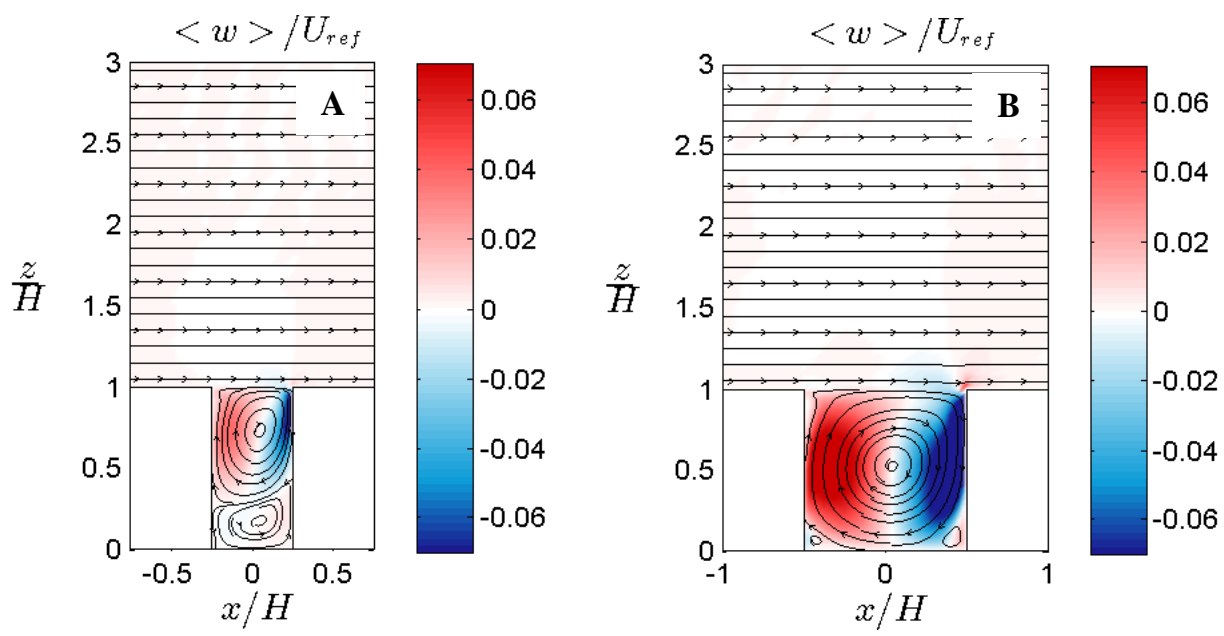

Figure 5. Streamlines of the mean velocity field and mean vertical velocity component, made non-dimensional by the freestream velocity $\left(\mathrm{U}_{\text {ref }}\right.$ at $\left.\mathrm{z} / \mathrm{H}=9\right)$. Building aspect ratio $\mathrm{AR}_{\mathrm{B}}=1$. Canyon aspect ratio: $\mathrm{AR}_{\mathrm{C}}=0.5(\mathrm{~A})$ and $\mathrm{AR}_{\mathrm{C}}=1(\mathrm{~B})$.
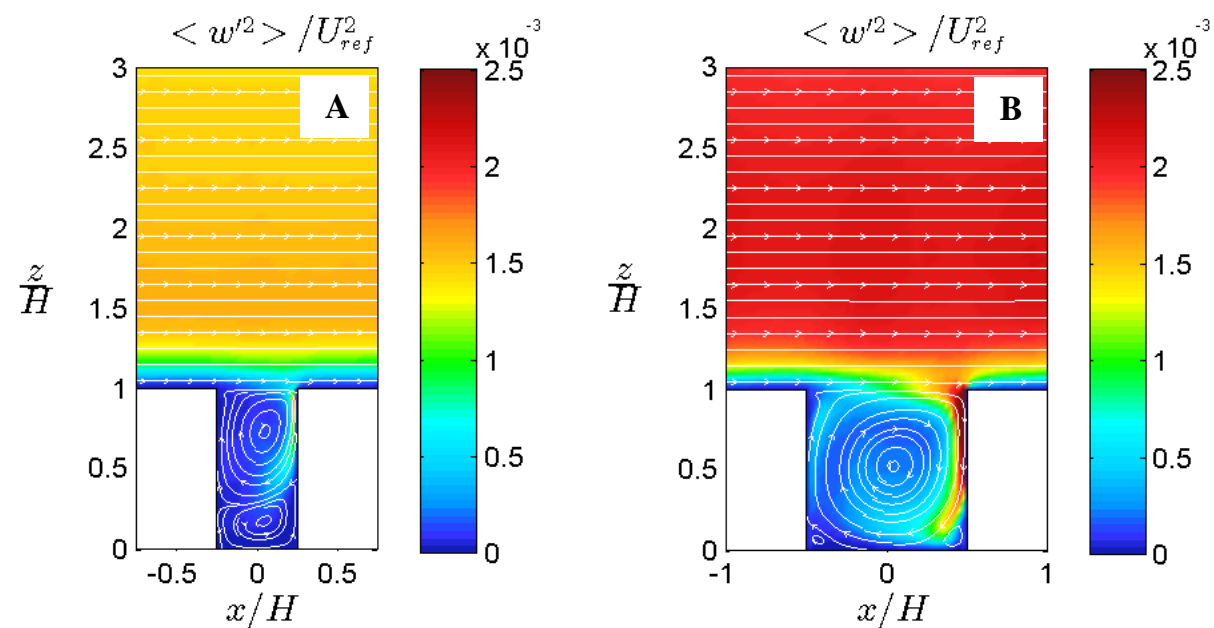

Figure 6. Streamlines of the mean velocity field and variance of the vertical velocity component, made non-dimensional by the freestream velocity $\left(\mathrm{U}_{\text {ref }}\right.$ at $\left.\mathrm{z} / \mathrm{H}=9\right)$. Building aspect ratio $\mathrm{AR}_{\mathrm{B}}=1$. Canyon aspect ratio: $\mathrm{AR}_{\mathrm{C}}=0.5(\mathrm{~A})$ and $\mathrm{AR}_{\mathrm{C}}=1(\mathrm{~B})$. 

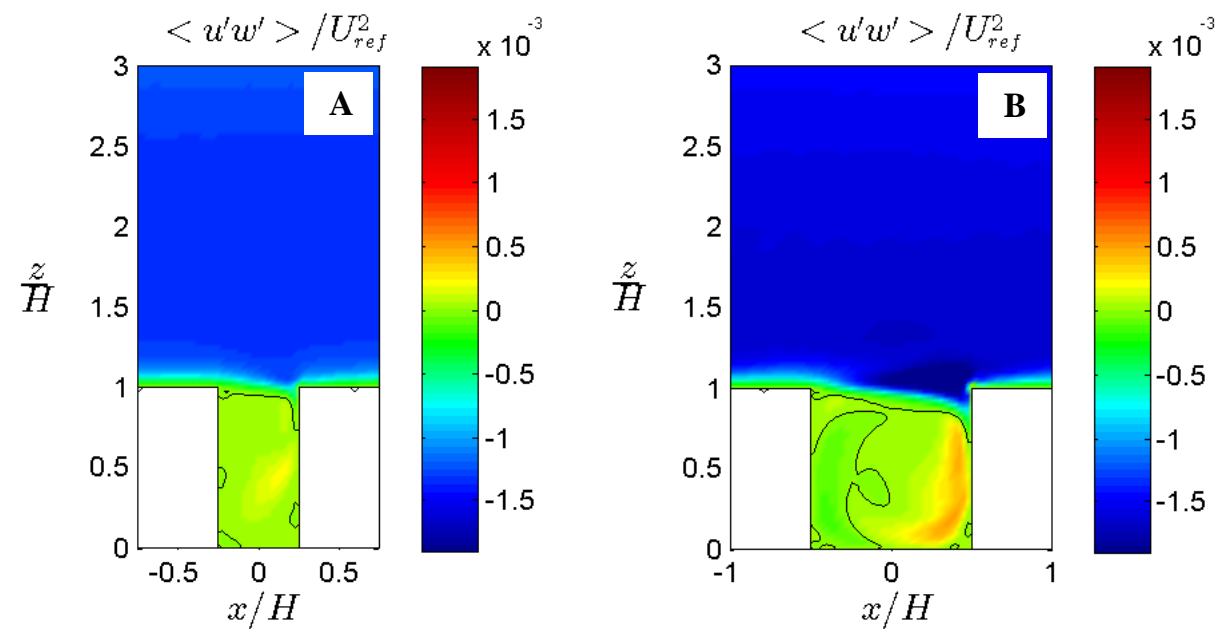

Figure 7. Mean vertical momentum flux, made non-dimensional by the free-stream velocity $\left(U_{\text {ref }}\right.$ at $\left.z / H=9\right)$. Building aspect ratio $A R_{B}=1$. Canyon aspect ratio: $A R_{C}=0.5$ (A) and $A R_{C}=1(B)$. The black line represents zero values.
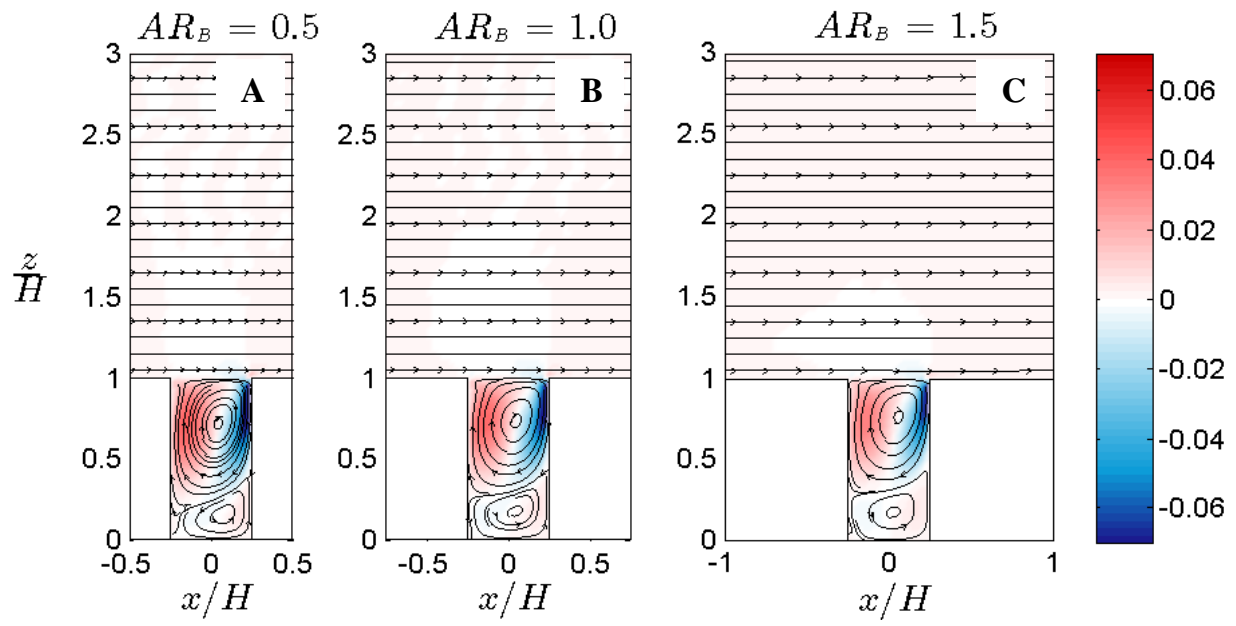

Figure 8. Streamlines of the mean velocity field and mean vertical velocity component, made non-dimensional by the freestream velocity $\left(\mathrm{U}_{\text {ref }}\right.$ at $\left.\mathrm{z} / \mathrm{H}=9\right)$. Building aspect ratio $\mathrm{AR}_{\mathrm{B}}=0.5(\mathrm{~A}), 1.5(\mathrm{~B}), 2.0(\mathrm{C})$. Canyon aspect ratio: $\mathrm{AR}_{\mathrm{C}}=0.5$. 

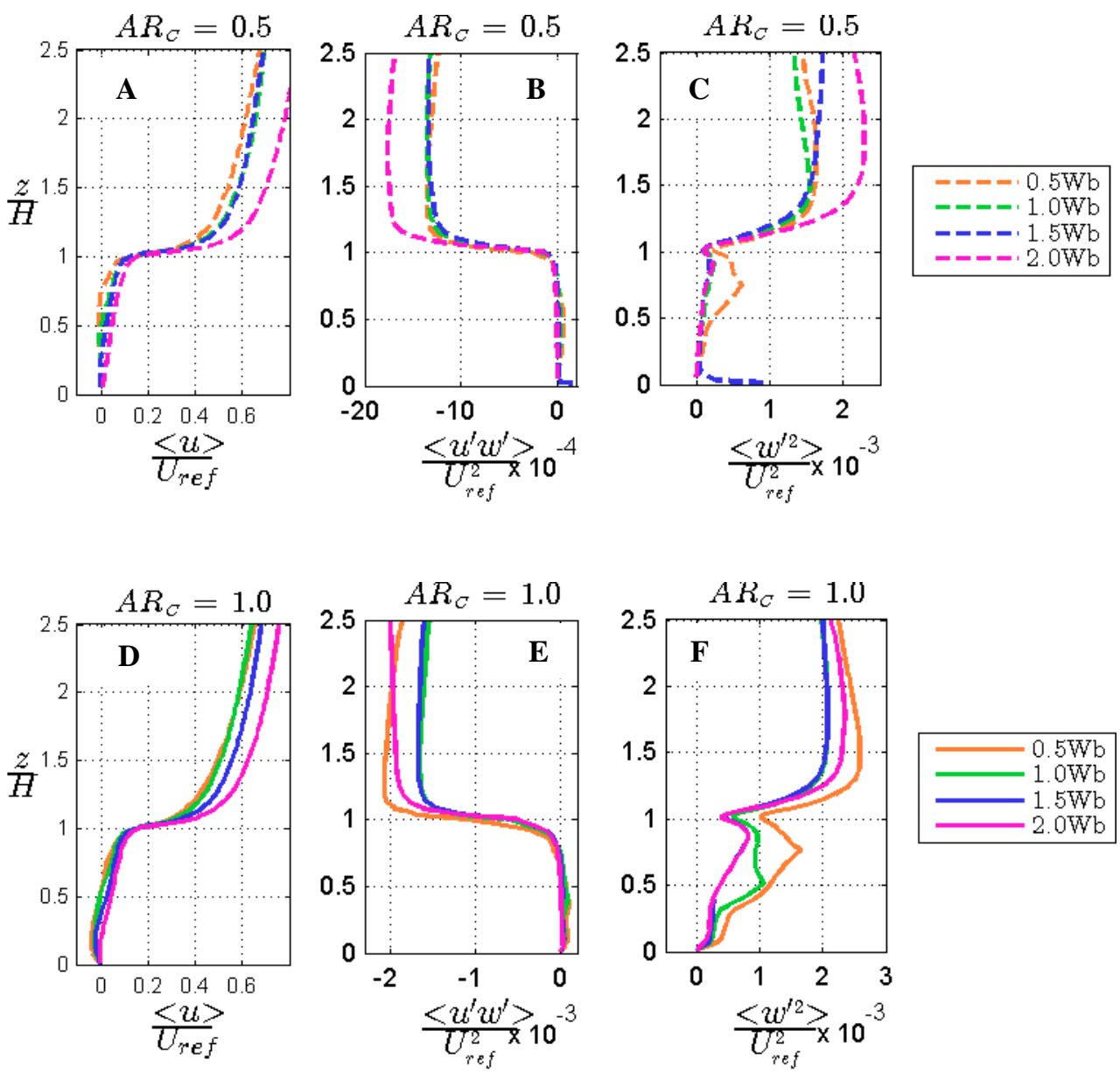

Figure 9. Non-dimensional, horizontally averaged, profiles for $A R_{C}=0.5(A-C)$ and $A R_{C}$ $=1.0(\mathrm{D}-\mathrm{F})$, and different buildings aspect ratios $\left(\mathrm{AR}_{\mathrm{B}}=0.5\right.$, orange line; $\mathrm{AR}_{\mathrm{B}}=1.0$, green line; $\mathrm{AR}_{\mathrm{B}}=1.5$ blue line; $\mathrm{AR}_{\mathrm{B}}=2.0$, pink line). Panels $\mathrm{A}, \mathrm{D}$ : mean horizontal velocity; panels $\mathrm{B}$, E: turbulent momentum flux; panels $\mathrm{C}-\mathrm{F}$ : variance of the vertical velocity. 

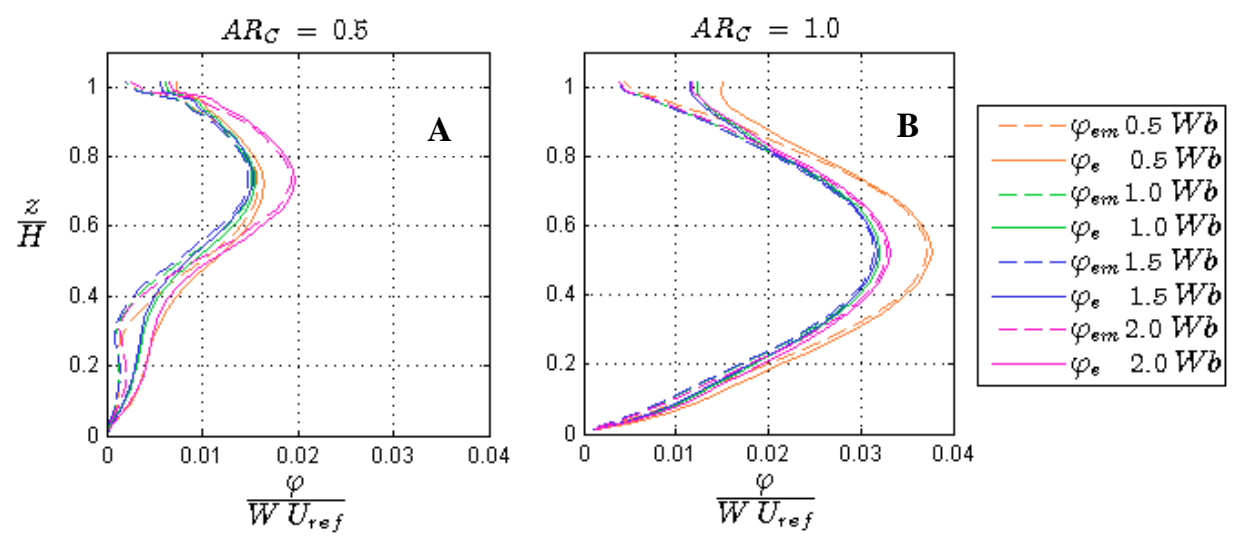

Figure 10. Non-dimensional vertical profiles of outflow rates computed for different $\mathrm{AR}_{\mathrm{B}}\left(\mathrm{AR}_{\mathrm{B}}=0.5\right.$, orange line; $\mathrm{AR}_{\mathrm{B}}=1.0$, green line; $\mathrm{AR}_{\mathrm{B}}=1.5$ blue line; $\mathrm{AR}_{\mathrm{B}}=2.0$, pink line) and $\mathrm{AR}_{\mathrm{C}}=0.5$ (panel $\mathrm{A}$ ) and $\mathrm{AR}_{\mathrm{C}}=1.0$ (panel $\mathrm{B}$ ). Solid lines indicate $\varphi_{e}$ and dashed lines $\varphi_{e m}$, made non-dimensional by the free-stream velocity $\mathrm{U}_{\text {ref }}$ and the canyon width W.

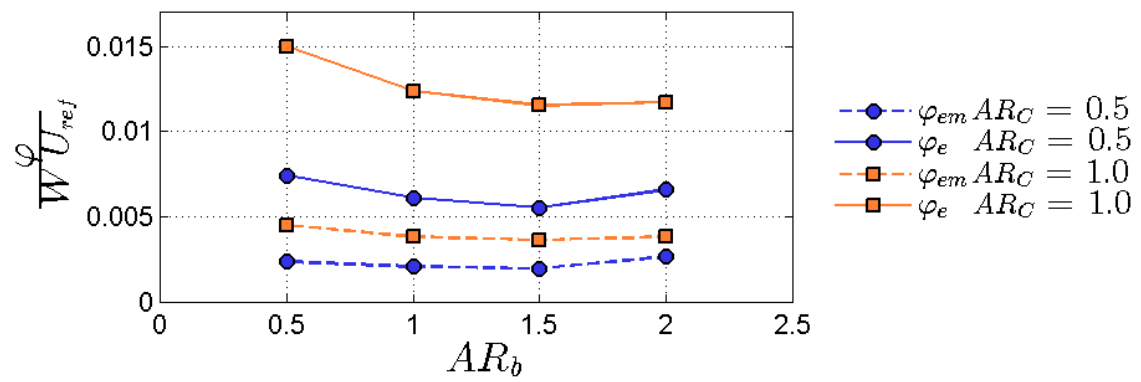

Figure 11. Non-dimensional profiles of the outflow rates computed at the roof level. Solid and dashed lines represent respectively $\varphi_{e}$ and $\varphi_{e m}$.

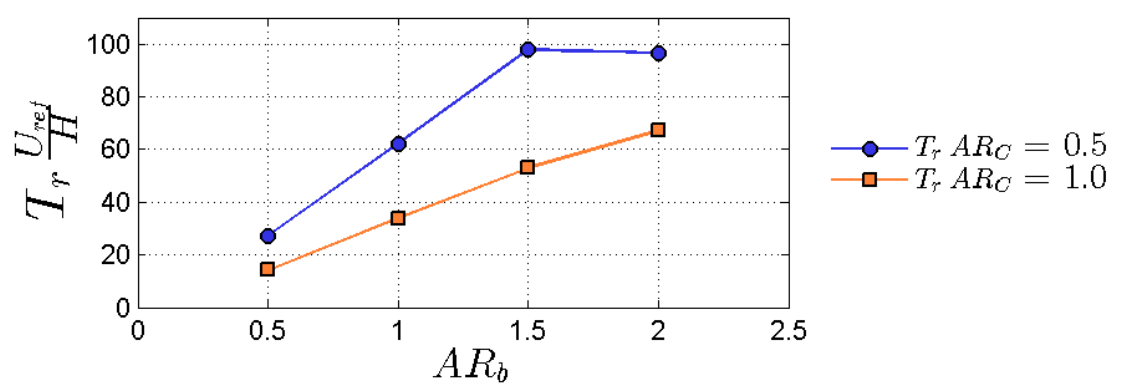

Figure 12. Mean residence time, $T_{r}$, as a function of the building aspect ratio for $\mathrm{AR}_{\mathrm{C}}=$ 0.5 (blue line with circles) and $\mathrm{AR}_{\mathrm{C}}=1.0$ (orange line with squares). 


\section{TABLES}

Table 1: Standard deviation with respect to the streamwise velocity $\left(\sigma_{\mathrm{u}}\right)$, and of skewness factor of the vertical velocity $\left(\sigma_{\mathrm{skw}}\right)$ calculated for the three profiles employed for validation on present data (Figure 2 and 3 ).

\begin{tabular}{lcc|cc|cc}
\hline & \multicolumn{2}{c|}{$\mathrm{x} / \mathrm{H}$} & \multicolumn{2}{c|}{$\mathrm{x} / \mathrm{H}$} & \multicolumn{2}{c}{$\mathrm{x} / \mathrm{H}$} \\
& \multicolumn{2}{c|}{0.4} & \multicolumn{2}{c|}{0} & \multicolumn{2}{c}{+0.4} \\
\hline & $\sigma_{\mathrm{u}}$ & $\sigma_{\text {skw }}$ & $\sigma_{\mathrm{u}}$ & $\sigma_{\text {skw }}$ & $\sigma_{\mathrm{u}}$ & $\sigma_{\text {skw }}$ \\
\hline Lab & 0.08 & 0.01 & 0.09 & 0.04 & 0.09 & 0.04 \\
Brown & 0.08 & 0.62 & 0.12 & 0.19 & 0.06 & 0.38 \\
Cheng & 0.05 & 0.14 & 0.04 & 0.15 & 0.04 & 0.18 \\
Cui & 0.06 & 0.77 & 0.07 & 0.20 & 0.07 & 0.43 \\
\hline
\end{tabular}

